\title{
Artificial Pancreas System for Type 1 Diabetes-Challenges and Advancements
}

\author{
Sachit Kapil ${ }^{1}$, Rishika Saini ${ }^{1}$, Subhash Wangnoo ${ }^{2}$ and Sangeeta Dhir ${ }^{3^{*}}$ \\ ${ }^{1}$ Department of Electrical Engineering, Arizona State University, Tempe, AZ, USA; ${ }^{2}$ Apollo Centre for Obesity \\ Diabetes \& Endocrinology, Apollo Hospitals, New Delhi, India; ${ }^{3}$ Department of Dentistry \& Clinical Research,
} Max Super Speciality Hospital, Saket, New Delhi, India

\begin{abstract}
Type 1 diabetes mellitus is a chronic autoimmune disease, requiring glucose monitoring and intensive insulin therapy. Its therapeutic management aims to restore normal $\mathrm{HbA} 1 \mathrm{C}$ and stabilize prandial and postprandial glucose levels. The burden of self-management of diabetes is high, and the growing requirement for blood glucose measuring devices presents a challenge. Such devices can continuously monitor glucose concentrations and automatically adjust insulin delivery rates, which in turn help to maintain blood glucose within a healthy range. The artificial pancreas system (so-called APS) technology has evolved rapidly over the past few years, capable of providing effective management of diabetes to improve quality of life of the type 1 diabetes mellitus patients. This review discusses the evolution of the APS technology and its progress in the various components: continuous subcutaneous insulin infusion, mathematical model, real-time continuous glucose monitoring, and control algorithms driving closed-loop control systems. The limitations and the proposed future directives are also discussed.
\end{abstract}

\section{Introduction}

Diabetes is a metabolic disease, characterized by variations in blood glucose levels (BGLs) due to either absolute insulin deficiency (type 1 diabetes mellitus, T1DM) or defective insulin action (type 2 diabetes mellitus, T2DM) or a combination of both. ${ }^{1}$ T1DM features autoimmune destruction of insulin-producing cells present in the pancreas, known as beta cells. ${ }^{2}$ This causes insufficient insulin production, thereby leading to a life-long dependency on administration of insulin to the body through external routes. A healthy pancreas releases insulin in response to elevated glucose levels in the body and helps in the transfer of glucose from the blood to the cells of the body. In order to mimic it for a diabetic patient, basal

Keywords: Artificial pancreas system; Type 1 diabetes; Diabetes; Pancreas; Glucose sensor.

Abbreviations: APS, artificial pancreas system; CSII, continuous subcutaneous insulin infusion; CGM, continuous glucose monitoring; T1DM, Type 1 diabetes mellitus; T2DM, Type 2 diabetes mellitus; CL, closed loop; SMBG, self-monitoring of blood glucose; BGL, blood glucose levels; SAP, sensor-augmented pump; PID, proportional integral derivative; MPC, model predictive controller; FLC, fuzzy logic controller; HIC, H infinity controller; ML, machine learning; RL, reinforcement learning; DIY, do-it-yourself.

Received: May 01, 2020; Revised: June 10, 2020; Accepted: June 11, 2020

${ }^{*}$ Correspondence to: Sangeeta Dhir, Department of Dentistry \& Clinical Research, Max Super Speciality Hospital, Saket, New Delhi, India. Tel: 91-9818181971, Email: sangeeta dhir@hotmail.com

How to cite this article: Kapil S, Saini R, Wangnoo S, Dhir S. Artificial Pancreas System for Type 1 Diabetes-Challenges and Advancements. Exploratory Research and Hypothesis in Medicine 2020;5(3):110-120. doi: 10.14218/ERHM.2020.00028. insulin is administered to replicate background insulin during fasting phases of the day and additional bolus insulin is administered during mealtimes. Switching between these basal and bolus doses at strategic times is the foundation for upcoming automated diabetes care technologies. Hyperglycemia (increased) or hypoglycemia (reduced) leads to macrovascular and microvascular complications. Even glycemic variability within normal ranges can lead to complications, underlying the concept of time in range (TIR). ${ }^{3}$ T1DM patients may experience frequent hypoglycemia episodes over 24 hours in a day. Since the brain uses glucose exclusively for energy, when blood glucose concentration drops, its functions are impaired.

With the burden of self-management falling on the patient, there is a growing need for devices that can monitor these levels continuously and then automatically adjust insulin delivery rates to help maintain blood glucose in an optimal range. Such devices are now being called 'artificial pancreatic systems (APSs)' or 'closedloop (CL) systems'. When augmented with accurate and reliable continuous glucose monitors, they can regulate glucose levels and better control a patient's glycemic status. APS consists of the following three components: an insulin pump, also known as continuous subcutaneous insulin infusion (CSII); a sensor, that continuously measures interstitial glucose concentrations (also known as continuous glucose monitoring (CGM)); and a controller, that contains and executes algorithms to calculate insulin levels and thereby control glucose. These components can be wired, made to communicate wirelessly, or integrated all onto a single device. ${ }^{4}$ APS can be categorized into two types, namely single-hormone systems, which only deliver insulin, and dual-hormone systems, which deliver both insulin and glucagon. The addition of glucagon 


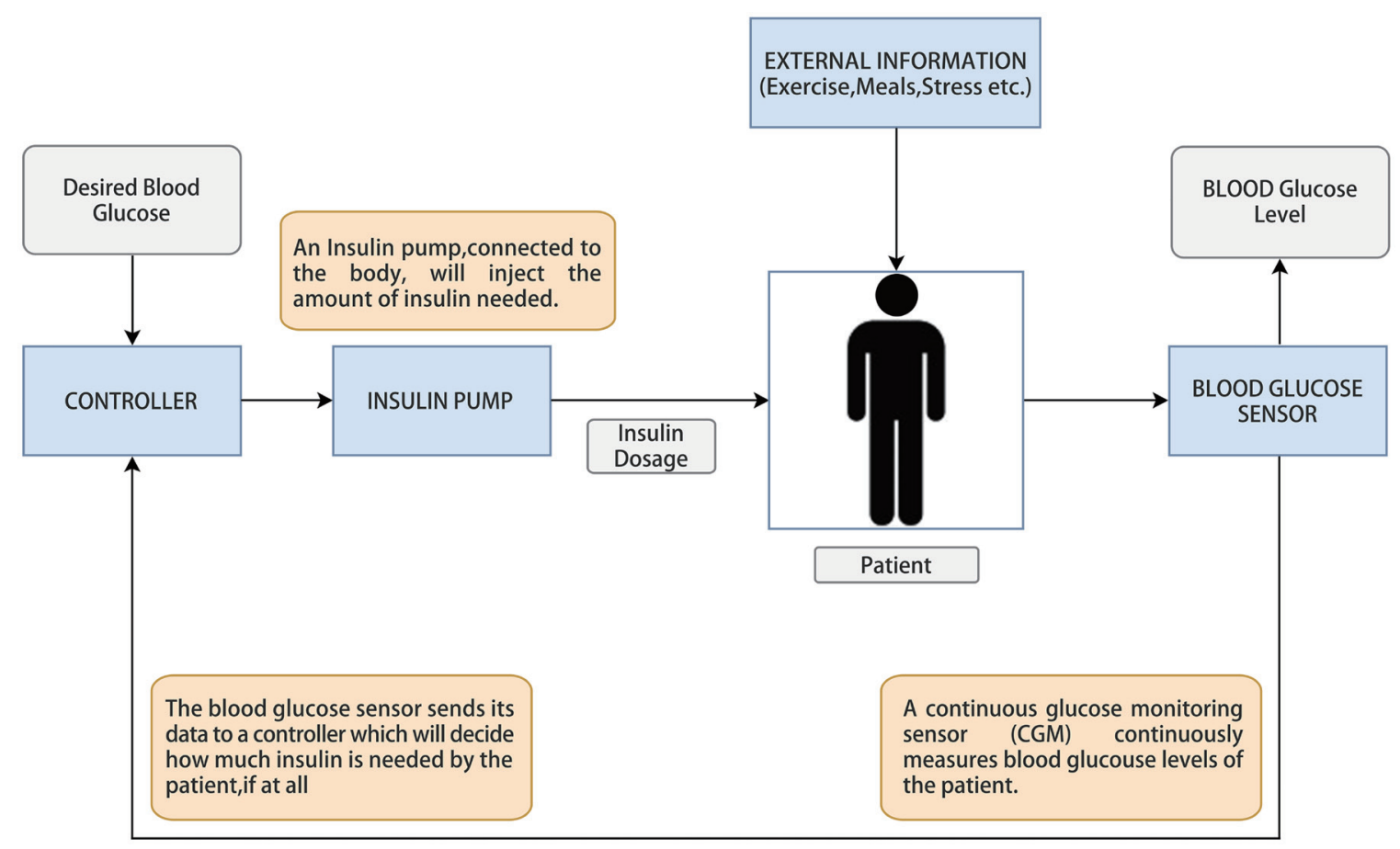

Fig. 1. Various components in an APS.

has the potential to further alleviate the risk of hypoglycemia but increases the system's complexity with separate drug reservoirs and infusion sets (Fig. 1).

\section{CSII/Insulin Pumps}

Portable CSII pumps first became possible in the early 1970s and showed achievement of improved glycemic control in early studies. The late 1990s and early 2000s saw rapid expansion in design and availability of CSII systems, as research showed improved outcomes with use of this technology. ${ }^{5}$ Insulin pumps deliver insulin by continuous infusion through a single subcutaneous site, which is replaced, on average, every 3 days. Only rapid-acting insulin is used, and the analogue insulins have gained popularity over this. A pump delivers programmable basal insulin around the clock that is tailored to the patient's 24-h glucose profile. Accurate estimates of the insulin bolus depend on the carbohydrate content of the food and the BGLs. Potential benefits of insulin pumps are significant reductions in A1C without increasing hypoglycemia, programmed insulin delivery that mimics the pancreatic function superior than injections, improved glycemic control with minimum glycemic variability, and minimize risk of hypoglycemia and need for hospitalization

\section{Indications of insulin pump}

Presence of persistently high $\mathrm{HbA1C}$ despite multidose insulin injection (MDII) therapy, recurring hypoglycemia, frequent wide glycemic variabilities, and persistent early morning hyperglycemia. Other indications are childhood and young adult age (as they typically desire fewer restrictions), preconception planning and pregnancy, gastroparesis, hectic lifestyle and frequent travel.
T2DM status is also an indication, according to its increased insulin requirements in general.

\section{Disadvantages of insulin pump}

Disruption of insulin administration (pump failure, kinked tubing, etc.) with subsequent development of severe hyperglycemia and diabetic ketoacidosis due to the short duration of the fast-acting insulin used in pumps. The sensor detects glucose in the interstitial fluid during its diffusion between the capillary and the target cell. ${ }^{5}$ Under steady-state conditions, interstitial glucose concentrations have been shown to be similar but not precisely equal to venous blood glucose concentrations in healthy individuals or animals. ${ }^{6}$ Rapid changes in blood glucose concentrations have been reported to affect the accuracy of the interstitial glucose sensing, causing the sensor to report glucose concentrations below their actual values. ${ }^{7,8}$

\section{CGM}

Self-monitoring of blood glucose (SMBG) has traditionally been used to monitor BGLs and confirm any instances of hypo/hyperglycemia. This enables the users to be independent and take corrective actions by adjusting the insulin dosage to counter external conditions. These glucose-meters have been available for more than 30 years now and come equipped with memory and software to store and analyze BGL data. ${ }^{9}$ For a diabetic user, BGL varies four to ten times a day, possibly due to differences in physical activity, lifestyle, food intake, and insulin injections. The act of monitoring and correcting situations for hypo/hyperglycemia is imperative for delaying the onset and slowing the progression of diabetic complications in the user. ${ }^{10}$

Glucose monitoring has transitioned from the SMBG to CGM owing to the demand for a less invasive method of measurement. 
Table 1. Glucose metabolism plant models

\begin{tabular}{|c|c|c|c|}
\hline Model & Year & Comments & Limitations \\
\hline $\begin{array}{l}\text { Bergman's } \\
\text { Minimal model } \\
\text { (pharmacokinetic } \\
\text { model) }\end{array}$ & 1981 & $\begin{array}{l}\text { Two-compartment model that describes } \\
\text { glucose-insulin interaction using three } \\
\text { ordinary differential equations }{ }^{8} \\
\text { Greatly widespread model }{ }^{19}\end{array}$ & $\begin{array}{l}\text { Does not consider exogenous insulin } \\
\text { infusion and } \mathrm{CH} \text { absorption from the } \text { gut }^{7} \\
\text { Assumes linear increase in rate } \\
\text { of insulin secretion }{ }^{19}\end{array}$ \\
\hline $\begin{array}{l}\text { Sorensen's model } \\
\text { (physiological model) }\end{array}$ & 1985 & $\begin{array}{l}\text { Uses various body organs to describe } \\
\text { the blood glucose system } \\
\text { Composed of } 19 \text { state equations, describing } \\
\text { insulin-glucose concentrations, and } \\
\text { incorporates the effect of glucagon }{ }^{21}\end{array}$ & $\begin{array}{l}\text { Unable to capture real hyperglycemic } \\
\text { extremes characteristic of T1DM }{ }^{7} \\
\text { Has been criticized for not accurately } \\
\text { representing observed glucose change }\end{array}$ \\
\hline Cobelli's model & 1998 & $\begin{array}{l}\text { Two-compartment minimal model } \\
\text { extended to include three subsystems } \\
\text { Effect of glucagon on glucose } \\
\text { metabolism is included, each depicted } \\
\text { with a single compartment }\end{array}$ & - \\
\hline $\begin{array}{l}\text { Hovorka model } \\
\text { (pharmacokinetic } \\
\text { model) }\end{array}$ & 2002 & $\begin{array}{l}\text { Non-linear model, presenting the relationship } \\
\text { between subcutaneous insulin infusion } \\
\text { and intravenous glucose concentrations } \\
\text { Provides the most comprehensive } \\
\text { understanding of glucose-insulin dynamics } \\
\text { Has been used in several clinical and in silico } \\
\text { studies in the field of artificial pancreas }{ }^{20}\end{array}$ & $\begin{array}{l}\text { Counter-regulatory hormones (e.g., } \\
\text { glucagon, epinephrine, etc.) have not } \\
\text { been considered in the model } \\
\text { Physiological factors, such as stress or sickness, } \\
\text { are also not considered along with exercise } \\
\text { Does not consider variations in the } \\
\text { absorption of different foods }{ }^{8}\end{array}$ \\
\hline $\begin{array}{l}\text { The Dalla Man } \\
\text { model and UVA/ } \\
\text { Padova simulator }\end{array}$ & $2006 / 2009$ & $\begin{array}{l}\text { Simulation model representing glucose-insulin } \\
\text { dynamics during meals using physiological } \\
\text { events occurring during digestion }{ }^{22} \\
\text { Simulator has replaced animal testing in } \\
\text { many studies, with preclinical testing }{ }^{23}\end{array}$ & - \\
\hline
\end{tabular}

CGM systems enable patients to monitor their BGL throughout the day, according to measurements taken at definite intervals of time as opposed to irregular, manually-set ones. These dynamic data have contributed towards better diabetes management, as they can be analyzed to recognize the rate of change as well as the direction of the glucose level changes. Additionally, CGM data give better insight into the impact that meals, exercises, stress, or illness may have on the user's glucose levels in real-time. ${ }^{11}$ This information enables users to proactively manage the increase or decrease in glucose levels. Additionally, it can be used in conjunction with insulin pumps (CSII pump technology) to better guide the insulin therapy (sensor-augmented pump (SAP) therapy). ${ }^{11,12}$ Of note, the first commercial CGM device was approved in 1999.

CGM systems consist of an electrochemical sensor, a reusable electronic transmitter, and a data display unit. ${ }^{13-15}$ They can be classified into three categories, as follows: (i) invasive (implantable) sensors; (ii) minimally invasive sensors; and (iii) noninvasive sensors, the placements of which depend on their glucose sensing mechanisms. ${ }^{15}$ These sensors provide BGL information every 5 to $10 \mathrm{~m}$, with a delay of 5 to $15 \mathrm{~m}$ approximately. ${ }^{14}$ The data are transmitted to a data display unit using a transmitter. A visualization of CGM data can be displayed on the data display unit for the user's benefit. The system can also analyze the data to generate historical trends or to alert the user of impending hypo/hyperglycemia episodes. ${ }^{11,14}$

Certain studies have shown that the use of CGM systems decreases the frequency of hypoglycemic episodes and thereby increases the time spent in normal-glycemia. ${ }^{14,16} \mathrm{~A}$ randomized study in adults showed that the users in the CGM group had a $72 \%$ reduction in hypoglycemic episodes. ${ }^{17}$ With the use of an integrated CGM system, alarms alerting the user of high or low glucose levels help increase the time spent in normal-glycaemia. With the emergence of these systems and the availability of remote monitoring, BGL data and trends can be shared with smartphones. This feature uses Wi-Fi or cell phone signals to upload data to the cloud and can provide access to physicians to view glucose trends and thereby alter insulin therapy. Additionally, parents can also access and monitor a young child's BGL data through such a feature. ${ }^{12,18}$

\section{Glucose metabolism plant model}

In a control system, the plant's output is regulated according to a desired set point using a controller. In this case, the output to be controlled is the blood glucose concentration and the patient acts as the plant. For simulation purposes, a glucose metabolism model is used that can then be made to act like a healthy individual or a T1DM patient as per the analysis being done.

Glucose metabolism models are generally formulated using differential equations that represent the biological dynamics of the human body. There are many models that have been proposed, which vary in form and details. Since they exhibit a huge variation, a direct comparison between them becomes a difficult task. ${ }^{6}$ Select models are reviewed in Table $1 . .^{7,8,19-23}$

\section{Controller Designs}

The main objective of a controller being implemented into an APS is to provide safe and effective glycemic control in T1DM. Quantitatively, this means maintaining the patient's blood glucose concentration within a target range of $70-140 \mathrm{mg} / \mathrm{dL}$ for 


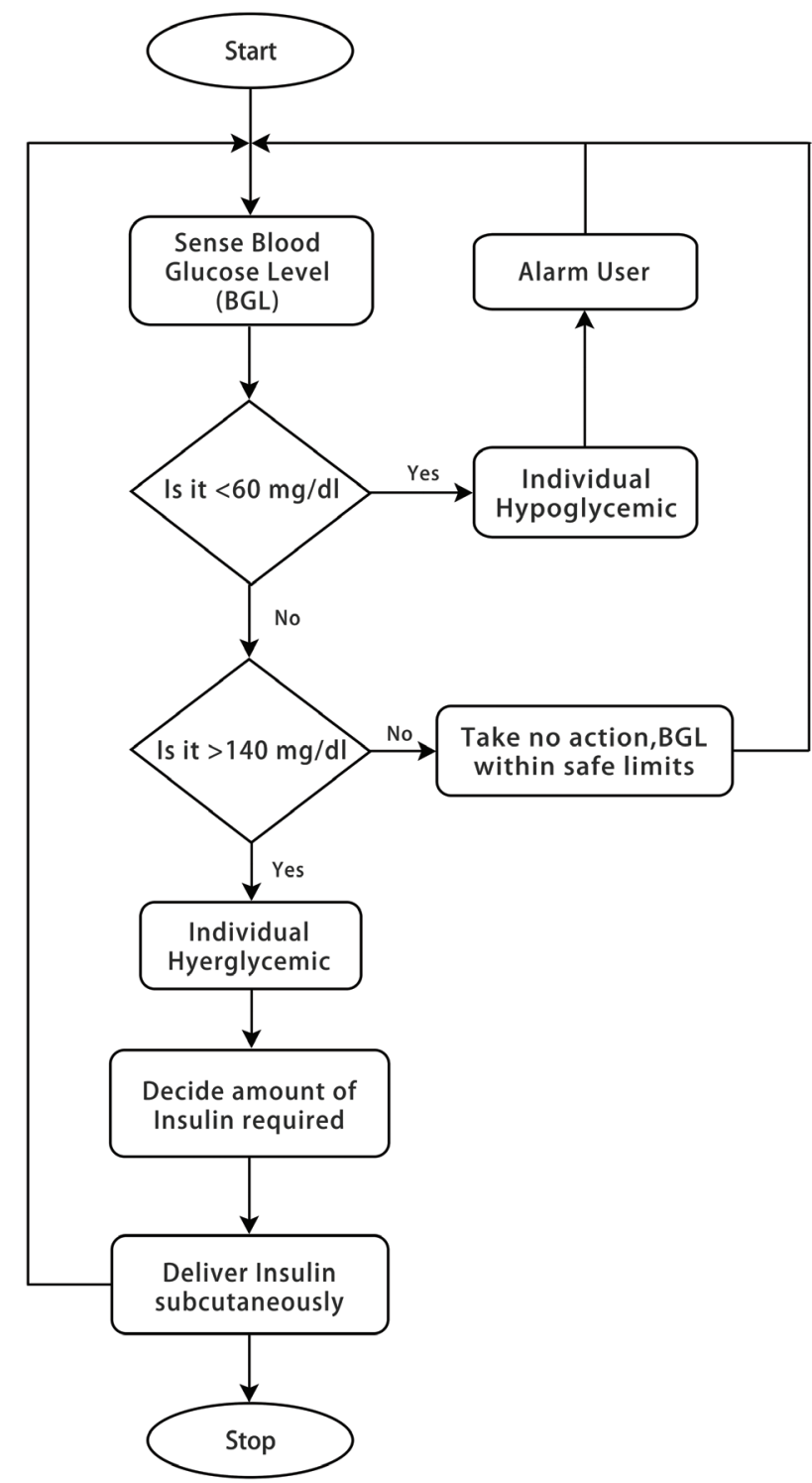

Fig. 2. Flowchart describing the algorithm being followed by the controller to determine the amount of insulin required.

as much time as possible by delivering doses of insulin. Additionally, the controller should be able to prevent hypoglycemic episodes as well. ${ }^{5}$ The controller requires a desired blood glucose value, which will be compared with the real-time blood glucose value received from the blood glucose sensor. ${ }^{24}$ The insulin value is sent to the pump, which may be either subcutaneous or intraperitoneal and which further delivers insulin to the patient. A control algorithm incorporated in a CL will calculate the required insulin value based on the above comparison. Figure 2 describes the controller algorithm for insulin. The various control algorithms are detailed below.

\section{PID controller}

The PID controller uses the difference between the reference (set point) and the process output value to generate an error signal $\mathrm{e}(\mathrm{t})$ that becomes the input signal to the controller. It has three elements, also called actions; these being: proportional (P), integral (I), and derivative (D) actions. The proportional gain $\mathrm{Kp}$ determines the magnitude of the instantaneous response of the controller to the error signal. The integral action with parameter $\mathrm{Ki}$ sums the error values over time to force the steady-state error to zero. The derivative term with parameter Kd responds to directions and magnitudes of change in outputs. ${ }^{8}$ A major advantage to the classical PID strategy is that the tuning parameters are a clear function of sample time, whereas other published strategies are specific to a given sample time. It has been argued that the function of pancreatic $\beta$ cells is similar in nature to PID and is composed of P, I and D components. The PID controller has certain limitations due to its purely reactive nature, i.e. it responds to changes in glucose concentration after they have occurred. It suffers most from the problem of having to optimize the trade-off between slow-pace regulation that is well-suited to mild control actions (applicable overnight), and postprandial regulation that calls for prompt and energetic corrections (post-meals). ${ }^{25}$ Additionally, it has been observed that a classical PID controller is unable to regulate BGLs well. ${ }^{8}$

\section{Model predictive controller (MPC)}

MPCs are closely related to the optimal control problem, where the control action is determined by real-time optimization. ${ }^{8}$ As a distinctive feature, MPCs can predict glucose dynamics, reduce or eliminate the inherent time delays between interstitial glucose monitoring and subcutaneous insulin infusion, and incorporate meal or hypoglycemia detection methods. ${ }^{26,27}$ They can be patientpersonalized, i.e. capable of learning specifics of a patient's daily routines (e.g., usual timing and content of meals and usual exercise timing, duration, and intensity) in order to optimize insulin delivery. This type of controller shows good performance to measured meals with proper carbohydrate-to-insulin ratio boluses. ${ }^{27}$ Studies have shown that there can be performance limitations while using an MPC. Unmeasured meals can cause high glucose peaks and slow disturbance rejection. Thus, meal detection and meal size estimation algorithms are developed to automatically administer meal insulin boluses as feed-forward action to unmeasured (unannounced) meals. ${ }^{27}$ Additionally, due to the predictive nature of the MPC model, it requires high and fast computational power for good results. Thus, hardware requirements play a big role in use of this model.

\section{Fuzzy logic controller}

Contrary to MPC and PID controllers, which use mathematical equations to describe the gluco-regulatory system, fuzzy logic controllers only depend on glucose management parameters, which have been determined by an expert diabetes clinician and codified for use in the controller. A dosing rules matrix identifies special glucose dynamics indicative of events that may require special treatment, such as meals. ${ }^{28}$ In fuzzy machines, the decision and the means of choosing that decision are based on fuzzy sets and fuzzy rules. A fuzzy set is a set without a crisp, clearly defined boundary; it can contain elements with only a partial degree of membership. Fuzzy logic-based APSs provide a simple way to arrive at a definite conclusion based upon vague, ambiguous, imprecise, noisy, or missing input information by mimicking and automating how a medical expert would make decisions. A fuzzy logic controller does not necessarily mimic the way the body would respond in 
Table 2. Overview of the select studies on APS controller design

\begin{tabular}{|c|c|c|c|}
\hline Author & Study design & Findings & Future recommendations \\
\hline $\begin{array}{l}\text { Lauren et } \\
\text { al., } 2015^{5}\end{array}$ & $\begin{array}{l}\text { Design utilizes rapid glucose sensing } \\
\text { and insulin action offered by the } \\
\text { intraperitoneal space to tune a PID } \\
\text { controller with insulin feedback to } \\
\text { provide safe and effective insulin delivery }\end{array}$ & $\begin{array}{l}\text { Control algorithm maintained BGLs } \\
\text { within the tight glycemic range of } \\
80-140 \mathrm{mg} / \mathrm{dL} 78 \% \text { of the time, with } \\
\text { no time spent in hypoglycemia }\end{array}$ & $\begin{array}{l}\text { Test this controller design with } \\
\text { an animal model to evaluate } \\
\text { in vivo performance }\end{array}$ \\
\hline $\begin{array}{l}\text { Clarke et } \\
\text { al., } 2009^{26}\end{array}$ & $\begin{array}{l}\text { Comparison analysis between personal } \\
\text { open-loop systems and a model } \\
\text { predictive } \mathrm{CL} \text { system to control BGL } \\
\text { overnight and post-breakfast meal }\end{array}$ & $\begin{array}{l}\text { Model predictive } C L \text { control of } \\
\text { BGLs is significantly superior to } \\
\text { open-loop control in preventing } \\
\text { overnight hypoglycemia }\end{array}$ & $\begin{array}{l}\text { Performance of the system in the } \\
\text { presence of external information, } \\
\text { such as exercise, variable meals } \\
\text { and stress, needs to be evaluated }\end{array}$ \\
\hline $\begin{array}{l}\text { Lee et al., } \\
2008^{27}\end{array}$ & $\begin{array}{l}\text { Implementing a human-friendly } \\
\text { modeling test, integrated with a MPC } \\
\text { formulation, meal detection, and } \\
\text { meal size estimation for } \mathrm{CL} \text { control }\end{array}$ & $\begin{array}{l}\text { The proposed CL framework } \\
\text { shows acceptable glucose control } \\
\text { performance under daily life situations } \\
\text { and can handle measured and } \\
\text { unmeasured meal disturbances }\end{array}$ & $\begin{array}{l}\text { Future research will incorporate } \\
\text { time-varying insulin sensitivity } \\
\text { to account for circadian effects }\end{array}$ \\
\hline $\begin{array}{l}\text { Mauseth } \\
\text { et al., } \\
2013^{28}\end{array}$ & $\begin{array}{l}\text { Evaluation of a fuzzy logic controller } \\
\text { with patients under bed rest in a very } \\
\text { controlled environment for a } 24-\mathrm{h} \text { period }\end{array}$ & $\begin{array}{l}7 \text { of the } 10 \text { subjects in the study, with } \\
\text { average blood glucose values of } 165 \\
\mathrm{mg} / \mathrm{dL} \text {, were within a specified target } \\
\text { blood glucose range ( } 70-200 \mathrm{mg} / \\
\mathrm{dL} \text { ) for } 76 \% \text { of the } 24-\mathrm{h} \text { study period }\end{array}$ & $\begin{array}{l}\text { Need for an extensive study for } \\
\text { the generalizability of findings } \\
\text { Additional studies need to test } \\
\text { system performance under } \\
\text { influence of external information }\end{array}$ \\
\hline $\begin{array}{l}\text { Aicha et } \\
\text { al., } 2015^{30}\end{array}$ & $\begin{array}{l}\text { A robust } \mathrm{H} \text {-infinity controller is employed } \\
\text { to regulate } \mathrm{BGL} \text { in T1DM patients, based } \\
\text { on the uncertainty principle of the system }\end{array}$ & $\begin{array}{l}\text { Designed controller proved effective } \\
\text { in achieving normoglycemic } \\
\text { and was robust to meal and } \\
\text { exercise disturbances }\end{array}$ & $\begin{array}{l}\text { Future work aims to } \\
\text { employ the } \mu \text { synthesis }\end{array}$ \\
\hline
\end{tabular}

order to balance BGLs, but rather it is based on how a practitioner or doctor would to want it. This is considered as both an advantage and disadvantage of this system. ${ }^{8}$

\section{H-infinity controller}

The uncertainty in sensor measurements and insulin absorption produces a special risk of instability in the computer control system, calling for complex mathematical treatments, such as $\mathrm{H}$-infinity theory for control algorithm design. ${ }^{29}$ The principle behind using an uncertain model controller like H-Infinity stems out from the fact that it is hard to derive the exact value of parameters in most biological systems. Therefore, all parameters of the model have been considered uncertain and parametric uncertainty forms the basis of this control design. Select studies on the controller designs are reviewed in Table 2.5,26-28,30

\section{Machine learning in APS development}

Machine learning enables systems to learn from existing CGM data of an individual, thus eliminating the need of complex mathematical representations of glucose homeostasis. These algorithms can analyze existing data, recognize complex patterns, and predict outputs based on its learning (Fig. 3).

Challenges arise for CL strategies when the complex physiology of glucose homeostasis is represented in mathematical models. Additionally, the variation in a patient's insulin absorption and action suggest the requirement for an individualized algorithm to

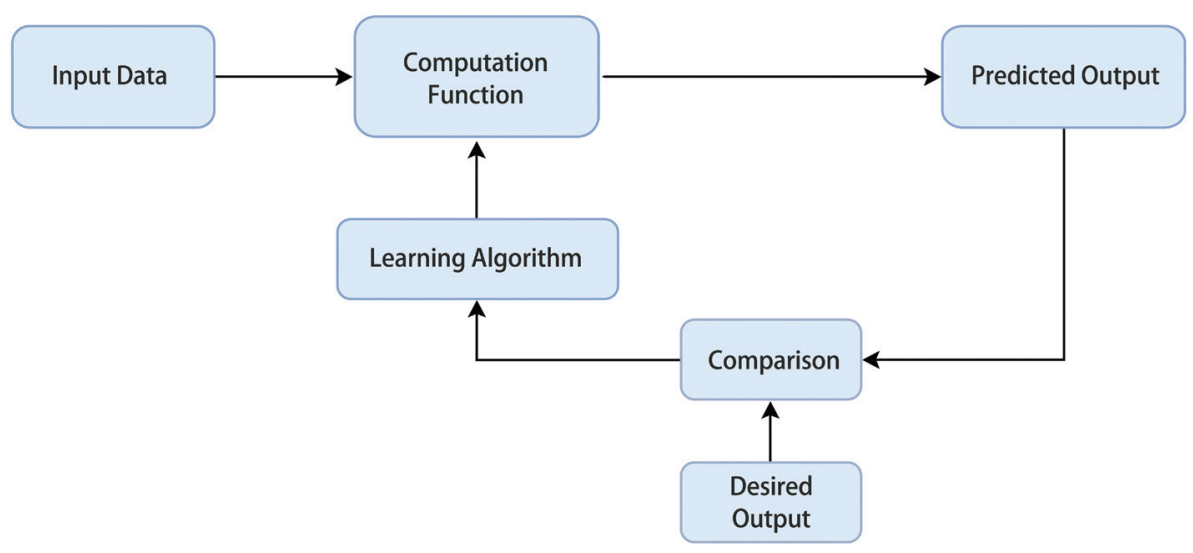

Fig. 3. Block diagram of a machine learning algorithm. 
Table 3. Select studies on implementing machine learning towards APS

\begin{tabular}{|c|c|c|c|}
\hline Author & Experimental design & Findings & Future recommendations \\
\hline $\begin{array}{l}\text { Daskalaki et } \\
\text { al., } 2016^{32}\end{array}$ & $\begin{array}{l}\text { Evaluated a RL algorithm (Actor-Critic } \\
\text { (AC) learning algorithm) for optimization } \\
\text { of daily basal insulin infusion and } \\
\text { insulin-carbohydrate ratio to provide } \\
\text { a personalized glucose regulation }\end{array}$ & $\begin{array}{l}95.66 \% \text { of time spent in normoglycemia } \\
\text { with meal uncertainty } \\
93.02 \% \text { of time spent in normoglycemia } \\
\text { with meal uncertainty and } \\
\text { insulin sensitivity variations } \\
\text { AC learned patient-specific characteristics } \\
\text { based on their glucose profile and } \\
\text { provided individualized insulin treatment }\end{array}$ & $\begin{array}{l}\text { Combination of } \mathrm{AC} \text { algorithm } \\
\text { with existing control strategies } \\
\text { can capture both the fast and } \\
\text { the slow glucose dynamics } \\
\text { An AC algorithm system can } \\
\text { act as a personalized advisory } \\
\text { system for the physicians }\end{array}$ \\
\hline $\begin{array}{l}\text { Bahremand } \\
\text { et al., } 2018^{33}\end{array}$ & $\begin{array}{l}\text { Artificial neural network, trained } \\
\text { on empirical data, predicts the } \\
\text { BGL of a virtual T1DM rat model } \\
\text { and a MPC controls the BGL } \\
\text { based on glucose predictions }\end{array}$ & $\begin{array}{l}\text { System maintained } B G L \text { within } \\
\text { the normal range }(\leq 90 \%) \text {, mean } \\
\text { absolute deviation: } 4.7 \mathrm{mg} / \mathrm{dL} \\
\text { Errors in predictions: }<5 \mathrm{mg} / \mathrm{dL} \\
(2 \%) \text { for } 5 \text {-m prediction } \&<11 \mathrm{mg} / \\
\mathrm{dL}(7 \%) \text { for } 30 \text {-m prediction }\end{array}$ & $\begin{array}{l}\text { In vivo implementation } \\
\text { to study its feasibility } \\
\text { Need to find ways to } \\
\text { measure food consumption } \\
\text { and exercise level during } \\
\text { experiments to obtain more } \\
\text { accurate virtual subjects }\end{array}$ \\
\hline $\begin{array}{l}\text { Rodríguez et } \\
\text { al., } 2019^{34}\end{array}$ & $\begin{array}{l}\text { Glucose-insulin dynamics data were } \\
\text { collected through various sensors } \\
\text { Evaluated an approach to use lesser } \\
\text { data for accurate person-centric } \\
\text { short-term prediction models }\end{array}$ & $\begin{array}{l}\text { Short-term predictions of } \\
\text { glucose levels (15-m horizon) } \\
\text { average error ( } 15.43 \mathrm{mg} / \mathrm{dL})\end{array}$ & $\begin{array}{l}\text { Effect of missing data (user } \\
\text { error or low-quality sensors) on } \\
\text { the accuracy of the prediction } \\
\text { models should be examined }\end{array}$ \\
\hline $\begin{array}{l}\text { Dutta et } \\
\text { al., } 2018^{35}\end{array}$ & $\begin{array}{l}\text { Evaluation of a personalized data-driven } \\
\text { approach, where a neural network } \\
\text { predicts future BGL of the user and } \\
\text { a MPC calculates optimal basal and } \\
\text { bolus insulin values in the presence of } \\
\text { unannounced meals and sensor errors }\end{array}$ & $\begin{array}{l}\text { System stays as close to the desired } \\
\text { target as possible, even in the presence } \\
\text { of unannounced meals and sensor errors }\end{array}$ & $\begin{array}{l}\text { Improvements towards } \\
\text { plant model construction } \\
\text { by using recurrent neural } \\
\text { networks could be explored }\end{array}$ \\
\hline
\end{tabular}

control BGLs. ${ }^{31-33}$ Machine learning techniques broadly fall under three categories, namely supervised, unsupervised and reinforcement learning (RL). Even though all three differ in their learning approach, each requires data that accurately represents the model that it wants to learn. There are two challenges associated with this approach. First, the data need to accurately represent the complex glucose-insulin dynamics of a patient and, second, training these learning algorithms requires a huge amount of data. This requires extensive patient monitoring performed in real-world conditions to obtain these data.

RL, a branch of machine learning, provides a flexible approach to maintaining normoglycemia in APSs. RL is an intensively active research field, which consists of algorithms that learn from data and optimize performance in an uncertain environment. ${ }^{31,32}$ The field of RL falls between supervised and unsupervised learning and includes problems where an agent algorithm attempts to improve performance at a given task over time by continual interaction with its environment. ${ }^{31} \mathrm{RL}$ algorithms can learn individual glucose patterns of a T1DM patient and provide adaptive drug delivery even in the presence of time delays and external disturbances. ${ }^{31}$ Select studies on machine learning are reviewed in Table $3 .{ }^{32-35}$

\section{Comparison between single-hormone and dual-hormone CL studies}

\section{Single-hormone CL studies}

Nimri et al. ${ }^{36}$ while exploring the capabilities of a single-hormone CL system specifically during night-time, stated that the system significantly reduced time spent in hypoglycemia and increased time spent in the target blood glucose concentration zone of 70-140 mg/ dL. The study demonstrated the feasibility of using CL insulin delivery in real-world settings. A randomized crossover study aimed to demonstrate robustness and generalizability of CL technology with the inclusion of a largely diverse group of people with T1DM over 12 weeks, with no restrictions on living conditions. Administering insulin through either hybrid CL or sensor-augmented pump therapy in these patients showed that the proportion of the time that glucose was within target was higher while using a CL system as compared to pump therapy ( $65 \% v s .54 \%$, respectively). Additionally, the time spent in hypoglycemia was also reduced. ${ }^{37}$

One of the first hybrid single-hormone CL systems was the MiniMed 670G Insulin Pump System by Medtronic. It has been approved for use in people aged 7 years and older and reportedly has more than 100,000 users. $^{2}$ A study was conducted to demonstrate the safety of this device, and showed that there were no episodes of severe hypoglycemia or ketoacidosis among the 12,389 patients involved. ${ }^{2}$ However, there were certain limitations observed in the system that included: frequent exits from the CL or automatic mode due to prolonged hyperglycemia; loss of sensor data; and delivery of insulin that was above or below the safety levels calculated. In the near future, several other companies are expected to release commercial single-hormone CL systems. The few names include: Tandem Diabetes Care; Insulet; Bigfoot Biomedical; Beta Bionics; Tidepool Loop; Roche; Admetsys; Defymed; and Diabeloop. $2,38,39$

\section{Dual-hormone CL studies}

Dual-hormone CL systems deliver both insulin and glucagon in 
order to tackle hyperglycemia as well as hypoglycemia. Small boluses of glucagon are given, in addition to the continuous supply of rapid-acting insulin. ${ }^{40}$ Meta-analysis has suggested that addition of glucagon is associated with a greater increase in time in target glucose range and a greater decrease in time in hypoglycemia when compared with single-hormone systems. ${ }^{41}$ Dual-hormone systems reported less episodes of hypoglycemia caused due to exercise, everyday activities, and during sleeping. ${ }^{42}$

Though it seems that a dual-hormone system would be the more efficient approach, there are certain limitations that are inhibiting the development of such a commercial device. ${ }^{2}$ There is a lack of commercially-available glucagon that is stable at room-temperature. Additionally, introducing a second hormone to be delivered increases the device's complexity and the limited number of longduration clinical studies poses a strong limitation in the commercialization of such a device. Such a dual-hormone system will require a dual-chamber pump, which is not commercially available and still in the development stages. A bigger challenge is that it requires two infusion sites and additional skill that has to be taught to the patient or the system. This can be a serious limitation when working with younger patients, for whom infusion site rotation will also be difficult. ${ }^{42}$

There is a minor difference in the performance of both singlehormone and dual-hormone systems in achieving glycemic control. Ahmed et al. ${ }^{43}$ in their randomized crossover trial compared the performance of both single and dual hormone systems along with the conventional insulin pump therapy, it was seen that over 24 hours , the time spent in the target glucose range was $62 \%, 63 \%$, and $51 \%$ respectively. The study concluded that single-hormone and dual-hormone APSs both provide better glycemic control than conventional insulin pump therapy. The study also found that the single-hormone APS might be sufficient for hypoglycemia-free overnight glycemic control.

\section{Impact of CL systems on users}

The feedback obtained from users of CL systems has suggested positive responses. The benefits shared by individuals include improved glucose control, which further led to reassurance, reduced anxiety, improved sleep, and relaxed eating habits. Additionally, users reported that the system helped them save time and reduced their need for self-monitoring. ${ }^{44}$ Other surveys reveal that users find easy start-up and calibration very beneficial, along with performance accuracy. There have been, however, some challenges expressed by users, the most common of which seemed to be trust in the CL device. Additional difficulties include technical trouble, excessive intrusiveness of an alarm feature, the equipment's bulky size, poor device connectivity, and inconvenience in incorporating CL systems into activities of daily life, such as exercise and bathing. Despite these, most participants in CL studies reported that they would personally continue using or would recommend CL therapy to a friend or relative because the clinical benefits outweigh system imperfections. ${ }^{2}$

\section{Comparison between fully automated and hybrid systems}

A hybrid CL system requires the user's initiation in order to deliver mealtime insulin boluses. There are studies that show such a model reduced hyperglycemia without causing any episodes of hypoglycemia. ${ }^{31}$ Though a hybrid system works well, the goal is to develop a fully automated system that requires no user interference. Such a system will automatically dose insulin without information about meals, thereby eliminating the need for user intervention. Despite this advantage, most CL approaches prefer using a hybrid system because glucose control is compromised with fully automated systems, owing to delayed absorption of subcutaneous insulin. Due to this, these systems may cause significant postprandial hyperglycemic excursions and late postprandial hypoglycemia when delivering boluses. ${ }^{45}$ Thus, hybrid systems may be better in functionality until developments are seen in fast-acting insulin for fully automated systems.

\section{'Do-it-Yourself' APS}

Owing to the intricate technicalities of an APS and how the smallest of errors in the system may be life-threatening for the user, we have not yet seen a commercially-available APS. Additionally, there are strict regulations and criteria that the device needs to fulfill in order to receive funding. ${ }^{46}$ Due to this slow progress towards commercialization, a group of technical enthusiasts have created a movement called \#WeAreNotWaiting. This group has evolved into an entire community that shares their technical knowledge and algorithms that can help them build a do-it-yourself APS. Some examples of such communities include 'OpenAPS', 'Loop', and 'AndroidAPS'. The 'OpenAPS' system was developed on a Raspberry Pi microcontroller system integrated with Medtronic insulin pumps. It has a feature that can suggest changes in insulin to carbohydrate ratios and insulin sensitivity factor settings, but it has limited pump compatibility as it was designed on an older version of the Medtronic insulin pump. The Loop can be used with an iPhone rather than a microcontroller. Its working differs in the sense that in order to calculate the required insulin value at any point of time, it will consider both the present glucose value as well as the value 30 minutes ago. A couple of drawbacks of this system is that it requires the use of a communication device and it uses an older version of the Medtronic insulin pump. The AndroidAPS uses an Android phone as its processing unit. A major advantage of this system is that it can work with many modern-day insulin pumps.

A do-it-yourself pancreatic system utilizes algorithms that are unregulated and untested in clinical trials, which makes them very unpredictable in terms of the risks they may induce on the user. Potential risks could also come out of user interaction with the system and the use of out-of-warranty pumps. ${ }^{42}$ Another challenge in the use of such devices is the inability to effectively communicate any errors and safety concerns with all the users.

Due to the challenges and risks associated with do-it-yourself systems, it can be very challenging for clinicians or doctors to ethically handle the situation where a patient may ask for advice on a platform such as the OpenAPS. Considering the current guidelines laid out for a doctor, it is recommended that the doctors do mention the existence of such a device to the patient asking but to not endorse or recommend it to them. ${ }^{47}$ Additionally, it is beneficial for the patients to be encouraged to share their data and information with their doctor in case they do choose to use such a system.

\section{APS and T2DM Management}

T2DM is the most prevalent chronic disease and is associated with premature mortality from multiple causes. Intensive insulin therapy (APS) when used in younger T2DM individuals helps in early glycemic control and prevents the loss of beta cell function and the expected diabetic micro- and macrovascular complications. ${ }^{48}$ However, in elderly people with T2DM and in people 
with advanced T2DM, aggressive glycemic control goals and undertreatment of hyperglycemia may complicate the management of geriatric syndromes and comorbid conditions. In the elderly population, APS usage might protect people from frailty, disability, and disease aggravation related to unrecognized episodes of massive dysglycemia. This could translate into lower rates of avoidable hospitalizations for actually ambulatory care-sensitive conditions. ${ }^{49}$

\section{Challenges in the APS Technology}

The development of an APS foresees certain challenges related to technological advancements in its components as briefed below.

\section{$C G M$}

1. The accuracy of interstitial glucose sensing is affected by rapid changes in BGL. This may cause the sensor to report glucose concentrations below their actual values. ${ }^{31}$ An incorrect BGL reading can lead to errors in insulin dosage being delivered to the user.

2. Studies have found sensor dropouts of blood glucose readings in the CGM sensors. This has been seen in cases where there was abnormal pressure applied on the sensor or if the user had laid directly down on it. ${ }^{12,26,50}$ Such dropouts have been observed to occur in commercially-available and approved glucose sensors and can cause problems in open-loop, low glucose suspend, or fully CL studies. ${ }^{50}$

3. Subcutaneous glucose sensors gathering data in real-time can incur a lag in measurement. An extensively large delay can lead to incorrect insulin dosages and hamper the system's overall performance. ${ }^{31}$

4. Medical insurances are a limiting factor for users whose insurance does not cover CGM systems or which provides limited coverage. These systems can be expensive when compared to SMBG devices, and regular replacements for sensors and transmitters add on to the eventual cost of the system. Typically, sensors will last from 7-14 days depending on the CGM device manufacturer, and their corresponding transmitters need to be replaced monthly to a couple times per year. ${ }^{11}$

5. Most CGM device manufacturers provide water resistance as a feature, but the extent to which the device is protected depends on the specific capabilities of the system. Abbott Freestyle Libre is water-resistant to 3 feet for up to $30 \mathrm{~m}$. The Medtronic Guardian Sensor 3 is water-resistant to 8 feet for up to $30 \mathrm{~m}$, and the Senseonics Eversense is water-resistant to 3.3 feet for up to 30 $\mathrm{m}$. Since the transmitter requires Bluetooth technology to transmit data to the receiver, CGM sensors may lose contact during water-based activities, such as showers, baths, and swimming. These dropouts in readings can cause problems in functionalities of the device. ${ }^{11}$

\section{CSII}

1. While using the subcutaneous route, there are delays seen in glucose sensing and insulin delivery. These delays make it difficult for the patient's body to be able to absorb and utilize the delivered insulin immediately after detecting an imbalance in BGL. ${ }^{51}$

2. A dual-hormone system is possibly an efficient approach for treating hypoglycemia; however, development of a commercial device is challenging. ${ }^{2}$ Glucagon, as a secondary hormone, faces challenges due to its instability in solution form. ${ }^{24}$ Introducing a second hormone increases the device's complexity and requires a dual-chamber pump system which is still not commercially-available. Finally, it requires two infusion sites, requiring additional skill that must be taught to the patient. ${ }^{42}$

3. Like CGM sensors, continued use of CSII technology is expensive and becomes an important issue in the care of patients with T1DM. ${ }^{11}$

\section{Controller}

1. The developed system should be able to regulate outputs in the presence of disturbances, such as exercise, mental stress, illness, and changes in meal composition.

2. Control algorithms need to personalize treatment to adapt to the inter/intra-individual variabilities in users, especially in their action on the unique glucose-insulin pattern. ${ }^{31}$

3. An APS involves integrating multiple components, such as the continuous glucose meter, insulin pump and the microcontroller. This integration leads to the possibility of multiple fault scenarios. It is important to investigate how the system will manage potential technical risks before moving onto commercialization.

\section{Future directions}

APS, over the years, has translated successfully from research to clinical practice. Cost-effective analyses are required for health care systems to support reimbursement of this technology. Based on the published literature on advancements in APSs, few recommendations are proposed for the future research. These include:

\section{$C G M$}

1. It is important for the system to use a reliable and long-lasting sensor to measure real-time blood glucose values accurately. It will make the device easily maintainable and affordable.

2. For better diabetes management during periods of rapid glucose changes, future CGM sensors need to reduce the lag in the measurement of the glucose concentrations.

3. Another area of development for CGM systems is to make them easy to wear. With smaller profiles and better adhesive strategies to keep them in place, the lifetime of a sensor can be improved, which will eventually make the system more affordable.

4. Introducing compatibility of CGM sensors with other independent insulin pumps makes the eventual goal of developing a CL APS for automatic insulin delivery achievable.

\section{CSII}

1. For the development of a fully automatic CL system, fasteracting insulin needs to be developed to reduce the delays in absorption of insulin delivered subcutaneously.

2. Long duration clinical studies assessing the feasibility of a dual-hormone system will help in faster commercialization. Additionally, focus on the development of a dual-chamber pump system will help achieve a fully functional APS. ${ }^{42}$ 
1. The control algorithm should be such that it automatically responds to external disturbances, such as physical exercise, meal composition, stress, and circadian variations in insulin sensitivity, without the need of any additional information from the patient. ${ }^{52,53}$

2. Controllers should show optimal performance with respect to time delays in order to minimize the time taken from glucose imbalance detection to the absorption of the required amount of insulin or glucagon. ${ }^{52}$

3. Any proposed control algorithms should be evaluated in vivo in order to obtain realistic results with respect to a human's glucose metabolism system. A steppingstone to human testing would be to test the control algorithm on animals with similar glucose metabolic systems, such as rats and pigs.

4. Prediction of type and intensity of physical activity using information from heart rate sensors and accelerometers can provide crucial information for the development of future artificial pancreas control algorithms. ${ }^{53}$

5. To accommodate unique variations in insulin sensitivity for individuals, future artificial pancreas algorithms need to be either personalized to respond to each situation separately or to closely mimic the physiological function of a working human pancreas for increased flexibility in operation. ${ }^{31,53}$

\section{Machine learning}

1. While applying machine learning techniques, it is important to make sure that the acquired data being used for training the model is representative, should have minimal noise, and the data set should neither be too little nor too large. ${ }^{31}$

2. A combination of machine learning and existing control strategies could be studied. A data-driven approach could provide short-term insulin updates that function independently of the control strategy. This will allow for a system to be built that is able to capture both the fast and the slow glucose dynamics. ${ }^{32}$

\section{Conclusion}

APS has a promising efficacious and safe modality of digital-age bioelectronics approach to the treatment of diabetes. A systematic review concluded that APS stabilizes the glycemic levels by maintaining an increased normoglycemic range, and reduced time in hypoglycemia and hyperglycemia. ${ }^{54}$ Evidence from several clinical research studies has demonstrated that CL systems are effective with improved glycemic outcomes and reduced hypoglycemia, and had positive end-user acceptance in children, adolescents, adults and pregnant women with T1DM. ${ }^{55}$ Limitations of current research evidence on APSs are related to inconsistency in outcome reporting, small sample size, and the short follow-up duration of individual trials. Clinical studies applying CL to particular cohorts of individuals with T1DM will be important in determining those who can benefit most from CL technology and will provide key evidence to support reimbursement by health care providers.

\section{Acknowledgments}

Sachit Kapil and Rishika Saini were involved in the designing of the APS prototype at Arizona State University.
None.

\section{Conflict of interest}

The authors declare that there is no conflict of interest.

\section{Author contributions}

Study concept and design (SD, SK, RS), acquisition of data (SD, RS, SK), analysis and interpretation of data (RS, SK), drafting of the manuscript (RS, SK), critical revision of the manuscript for important intellectual content (SW, SD, SK), administrative, technical, or material support, study supervision (SK, SD).

\section{References}

[1] Marchetti G, Barolo M, Jovanovič L, Zisser H, Seborg DE. A Feedforward-Feedback Glucose Control Strategy for Type 1 Diabetes Mellitus. J Process Control 2008;18(2):149-162. doi:10.1016/j.jprocont. 2007.07.008.

[2] Boughton CK, Hovorka R. Advances in Artificial Pancreas Systems. Sci TransI Med 2019;11(484):eaaw4949. doi:10.1126/scitranslmed. aaw4949.

[3] Battelino T, Danne T, Bergenstal RM, Amiel SA, Beck R, Biester T, et al. Clinical Targets for Continuous Glucose Monitoring Data Interpretation: Recommendations from the International Consensus on Time in Range. Diabetes Care 2019;42(8):1593-1603. doi:10.2337/dci190028.

[4] Kropff J, DeVries JH. Continuous Glucose Monitoring, Future Products, and Update on Worldwide Artificial Pancreas Projects. Diabetes Technol Ther 2016;18(Suppl 2):S253-S263. doi:10.1089/dia.2015.0345.

[5] Huyett LM, Dassau E, Zisser HC, Doyle FJ 3rd. Design and Evaluation of a Robust PID Controller for a Fully Implantable Artificial Pancreas. Ind Eng Chem Res 2015;54(42):10311-10321. doi:10.1021/acs. iecr.5b01237.

[6] Steil GM, Clark B, Kanderian S, Rebrin K. Modeling Insulin Action for Development of a closed-loop Artificial Pancreas. Diabetes Technol Ther 2005;7(1):94-108. doi:10.1089/dia.2005.7.94.

[7] Cobelli C, Man CD, Sparacino G, Magni L, Nicolao GD, Kovatchev BP. Diabetes: Models, Signals, and Control. IEEE Rev Biomed Eng 2009; 2:54-96. doi:10.1109/RBME.2009.2036073.

[8] Cinar A, Turksoy K. Advances in Artificial Pancreas Systems: Adaptive and Multivariable Predictive Control. Springer International Publishing, 2018.

[9] Rodbard D. Optimizing Display, Analysis, Interpretation and Utility of Self-Monitoring of Blood Glucose (SMBG) Data for Management of Patients with Diabetes. J Diabetes Sci Technol 2007;1(1):62-71. doi:10.1177/193229680700100111.

[10] Didyuk O, Econom N, Guardia A, Livingston K, Klueh U. Continuous Glucose Monitoring Devices: Past, Present, and Future Focus on the History and Evolution of Technological Innovation. J Diabetes Sci Technol 2020:1932296819899394. doi:10.1177/1932296819899394.

[11] Allen N, Gupta A. Current Diabetes Technology: Striving for the Artificial Pancreas. Diagnostics (Basel) 2019;9(1):31. doi:10.3390/diagnostics9010031.

[12] Forlenza GP, Buckingham B, Maahs DM. Progress in Diabetes Technology: Developments in Insulin Pumps, Continuous Glucose Monitors, and Progress towards the Artificial Pancreas. J Pediatr 2016;169:1320. doi:10.1016/j.jpeds.2015.10.015.

[13] Liebl A, Henrichs HR, Heinemann L, Freckman G, Biermann E, Thomas $\mathrm{A}$, et al. Continuous glucose monitoring: evidence and consensus statement for clinical use. J Diabetes Sci Technol 2013;7(2):500-519. 
doi:10.1177/193229681300700227.

[14] van Beers CA, DeVries JH. Continuous Glucose Monitoring: Impact on Hypoglycemia. J Diabetes Sci Technol 2016;10(6):1251-1258. doi:10.1177/1932296816653411.

[15] Vaddiraju S, Burgess DJ, Tomazos I, Jain FC, Papadimitrakopoulos F. Technologies for continuous glucose monitoring: current problems and future promises. J Diabetes Sci Technol 2010;4(6):1540-1562. doi:10.1177/193229681000400632.

[16] Van Beers CA, De Vries JH, Kleijer SJ, Smits MM, Geelhoed-Duijvestijn $\mathrm{PH}$, Kramer $\mathrm{MH}$, et al. Continuous glucose monitoring for patients with type 1 diabetes and impaired awareness of hypoglycaemia (IN CONTROL): a randomised, open-label, crossover trial. Lancet Diabetes Endocrinol 2016;4(11):893-902. doi:10.1016/S2213-8587(16) 30193-0.

[17] Heinemann L, Freckmann G, Ehrmann D, Faber-Heinemann G, Guerra S, Waldernmaier $\mathrm{D}$, et al. Real-time continuous glucose monitoring in adults with type 1 diabetes and impaired hypoglycaemia awareness or severe hypoglycaemia treated with multiple daily insulin injections (HypoDE): a multicentre, randomised controlled trial. Lancet 2018;391(10128):1367-1377. doi:10.1016/S0140-6736(18)30297-6.

[18] Burckhardt MA, Roberts A, Smith GJ, Abraham MB, Davis EA, Jones TW. The Use of Continuous Glucose Monitoring with Remote Monitoring Improves Psychosocial Measures in Parents of Children with Type 1 Diabetes: A Randomized Crossover Trial. Diabetes Care 2018;41(12):2641-2643. doi:10.2337/dc18-0938.

[19] Palumbo P, Ditlevsen S, Bertuzzi A, De Gaetano A. Mathematical modeling of the glucose-insulin system: a review. Math Biosci 2013;244(2):69-81. doi:10.1016/j.mbs.2013.05.006.

[20] Wu ZM. Mathematical Models with Delays for Glucose-Insulin Regulation and Applications in Artificial Pancreas (a PhD theses). Available from: http://scholarbank.nus.edu.sg/handle/10635/37897. Accessed May 1, 2020

[21] Lynch SM, Bequette BW. Estimation-based model predictive contro of blood glucose in type I diabetics: a simulation study. Proceedings of the IEEE 27th Annual Northeast Bioengineering Conference (Cat. No.01CH37201). IEEE, 2001:79-80. doi:10.1109/NEBC.2001.924729.

[22] Bhonsle S, Saxena S. A review on control-relevant glucose-insulin dynamics models and regulation strategies. J Systems and Control Engineering 2020;234(5):596-608. doi:10.1177/0959651819870328.

[23] Kushner T, Bequette BW, Cameron F, Forlenza G, Maahs D, Sankaranarayanan S. Liò P, Zuliani P. Models, Devices, Properties, and Verification of Artificial Pancreas Systems. Automated Reasoning for Systems Biology and Medicine. Computational Biology, vol 30. Cham, Springer, 2019. doi:10.1007/978-3-030-17297-8_4.

[24] Doyle FJ 3rd, Huyett LM, Lee JB, Zisser HC, Dassau E. Closed-Loop Artificial Pancreas Systems: Engineering the Algorithms. Diabetes Care 2014;37(5):1191-1197. doi:10.2337/dc13-2108.

[25] Cobelli C, Renard E, Kovatchev B. Artificial Pancreas: Past, Present, Future. Diabetes 2011;60(11):2672-2682. doi:10.2337/db11-0654.

[26] Clarke WL, Anderson S, Breton M, Patek S, Kashmer L, Kovatchev B. Closed-Loop Artificial Pancreas Using Subcutaneous Glucose Sensing and Insulin Delivery and a Model Predictive Control Algorithm: the Virginia Experience. J Diabetes Sci Technol 2009;3(5):1031-1038. doi:10.1177/193229680900300506.

[27] Lee H, Bequette BW. A Closed-loop Artificial Pancreas based on MPC: human-friendly identification and automatic meal disturbance rejection. IFAC Proceedings Volumes 2008;41(2):4252-4257. doi:10.3182/20080706-5-KR-1001.00715.

[28] Mauseth R, Hirsch IB, Bollyky J, Kircher R, Matheson D, Sanda S, et al. Use of a "fuzzy logic" controller in a closed-loop artificial pancreas. Diabetes Technol Ther 2013;15(8):628-633. doi:10.1089/ dia.2013.0036.

[29] Jaremko J, Rorstad O. Advances Toward the Implantable Artificial Pancreas for Treatment of Diabetes. Diabetes Care 1998;21(3):444450. doi:10.2337/diacare.21.3.444.

[30] Aicha H, Mourad A. H-infinity controller design for blood glucose regulation in diabetes patients in the presence of uncertain parameters. 2015 3rd International Conference on Control, Engineering \& Information Technology (CEIT). IEEE, 2015:1-6. doi:10.1109/ ceit.2015.7233036.

[31] Bothe MK, Dickens L, Reichel K, Tellmann A, Ellger B, Westphal
$\mathrm{M}$, et al. The use of reinforcement learning algorithms to meet the challenges of an artificial pancreas. Expert Rev Med Devices 2013;10(5):661-673. doi:10.1586/17434440.2013.827515.

[32] Daskalaki E, Diem P, Mougiakakou SG. Model-Free Machine Learning in Biomedicine: Feasibility Study in Type 1 Diabetes. PLoS One 2016;11(7):e0158722. doi:10.1371/journal.pone.0158722.

[33] Bahremand S, Ko HS, Balouchzadeh R, Lee HF, Park S, Kwon G. Neural network-based model predictive control for type 1 diabetic rats on artificial pancreas system. Med Biol EngComput 2019;57(1):177191. doi:10.1007/s11517-018-1872-6.

[34] Rodríguez-Rodríguez I, Chatzigiannakis I, Rodríguez JV, Maranghi M, Gentili M, Zamora-Izquierdo MÁ. Utility of Big Data in Predicting Short-Term Blood Glucose Levels in Type 1 Diabetes Mellitus Through Machine Learning Techniques. Sensors (Basel) 2019;19(20):4482. doi:10.3390/s19204482.

[35] Dutta S, Kushner T, Sankaranarayanan S. Češka M, Šafránek D. Robust Data-Driven Control of Artificial Pancreas Systems Using Neural Networks. Computational Methods in Systems Biology. CMSB 2018. Lecture Notes in Computer Science, vol 11095. Cham, Springer, 2018.

[36] Nimri R, Muller I, Atlas E, Miller S, Fogel A, Bratina N, et al. Logic overnight control for 6 weeks of home use in patients with type 1 diabetes: randomized crossover trial. Diabetes Care 2014;37(11):30253032. doi:10.2337/dc14-0835.

[37] Tauschmann M, Thabit H, Bally L, Allen JM, Hartnell S, Wilinska $\mathrm{ME}$, et al. Closed-loop insulin delivery in suboptimally controlled type 1 diabetes: a multicentre, 12-week randomised trial. Lancet 2018;392(10155):1321-1329. doi:10.1016/S0140-6736(18)31947-0.

[38] New Diabetes Technology to Watch for in 2020. Available from: https://www.healthline.com/diabetesmine/diabetes-tech-spectations-2020. Accessed May 1, 2020.

[39] Nimri R, Piper M, Pinsker JE, Dassau E. Decision Support Systems and Closed Loop. Diabetes Technol Ther 2020;22(S1):S47-S62. doi:10.1089/dia.2020.2504.

[40] Peters TM, Haidar A. Dual-hormone artificial pancreas: benefits and limitations compared with single-hormone systems. Diabet Med 2018;35(4):450-459. doi:10.1111/dme.13581.

[41] Weisman A, Bai JW, Cardinez M, Kramer CK, Perkins BA. Effect of artificial pancreas systems on glycaemic control in patients with type 1 diabetes: A systematic review and meta-analysis of outpatient randomised controlled trials. Lancet Diabetes Endocrinol 2017;5(7):501-512. doi:10.1016/S2213-8587(17)30167-5.

[42] Haidar A. Insulin-and-Glucagon Artificial Pancreas Versus Insulin-Alone Artificial Pancreas: A Short Review. Diabetes Spectr 2019;32(3):215-221. doi:10.2337/ds18-0097.

[43] Haidar A, Legault L, Messier V, Mitre TM, Leroux C, Rabasa-Lhoret R. Comparison of Dual-Hormone Artificial Pancreas, Single-Hormone Artificial Pancreas, Single-Hormone Artificial Pancreas,and Conventional Insulin Pump Therapy for Glycaemic Control in Patients with Type 1 Diabetes: An Open-Label Randomised Controlled Crossover Trial. Lancet Diabetes Endocrinol 2015;3(1):17-26. doi:10.1016/ S2213-8587(14)70226-8.

[44] Farrington C. Psychosocial impacts of hybrid closed-loop systems in the management of diabetes: a review. Diabet Med 2018;35(4):436449. doi:10.1111/dme.13567.

[45] Boughton CK, Hovorka R. Automated Insulin Delivery in Adults. Endocrinol Metab Clin North Am 2020;49(1):167-178. doi:10.1016/j. ecl.2019.10.007.

[46] Crabtree TSJ, McLay A, Wilmot EG. DIY artificial pancreas systems: here to stay? Practical Diabetes 2019;36(2):63-68. doi:10.1002/ pdi.2216.

[47] Shaw D, Crabtree TSJ, Hammond P, McLay A, Wilmot EG. The DIY artificial pancreas system: an ethical dilemma for doctors. Diabet Med 2020;doi:10.1111/dme.14270.

[48] Testa R, Bonfigli AR, Prattichizzo F, La Sala L, De Nigris V, Ceriello A. The "metabolic memory" theory and the early treatment of hyperglycemia in prevention of diabetic complications. Nutrients 2017;9(5):437. doi:10.3390/nu9050437.

[49] Kirkman MS, Briscoe VJ, Clark N, Florez H, Haas LB, Halter JB, et al. Diabetes in older adults. Diabetes Care 2012;35(12):2650-2664. doi:10.2337/dc12-1801.

[50] Baysal N, Cameron F, Buckingham BA, Wilson DM, Chase HP, Maahs 
DM, et al. A Novel Method to Detect Pressure-Induced Sensor Attenuations (PISA) in an Artificial Pancreas. J Diabetes Sci Technol 2014;8(6):1091-1096. doi:10.1177/1932296814553267.

[51] Hernando ME, García-Sáez G, Martínez-Sarriegui I, Rodríguez-Herrero A, Pérez-Gandía C, Rigla $M$, et al. Automatic data processing to achieve a safe telemedical artificial pancreas. J Diabetes Sci Technol 2009;3(5):1039-1046. doi:10.1177/193229680900300507.

[52] Lunze K, Singh T, Walter M, Brendel MD, Leonhardt S. Blood glucose control algorithms for type 1 diabetic patients: A methodological review. Biomedical Signal Processing and Control 2013;8(2):107-119. doi:10.1016/j.bspc.2012.09.003.
[53] Hernando ME, García-Sáez G, Gómez EJ, Pérez-Gandía C, RodríguezHerrero A. Automated Insulin Delivery: The Artificial Pancreas Technical Challenges. Am J Ther 2020;27(1):e62-e70. doi:10.1097/ MJT.0000000000001086.

[54] Bekiarai E, Kitsios K, Thabit H, Tauschmann M, Athanasiadou E, Karagiannis $\mathrm{T}$, et al. Artificial pancreas treatment for outpatients with type 1 diabetes: systematic review and meta-analysis. BMJ 2018;361:k1310. doi:10.1136/bmj.k1310.

[55] Boughton CK, Hovorka R. Is an Artificial Pancreas (Closed-Loop System) for Type 1 Diabetes Effective? Diabet Med 2019;36(3):279-286. doi:10.1111/dme.13816. 